culties as far as possible. Proofs of statements are printed in smaller type, and the general argument can be followed quite readily. Misconceptions of the position of the exponent of the Principle are frequent, and the exponent is not always free from blame. In these circumstances we welcome the explicit statement on p. II -and the statement cannot be criticised-that while the Principle of Relativity cannot say what are the equations for bodies the motion of which is not uniform, it can say what they may be, and it therefore gives a powerful means of devising such equations to be tested by experiment. A similar definiteness is found in connection with the vexed problem of rotation.

The third part of the work is devoted to the necessary modifications of mechanical theory, on the supposition that the Principle is universal. Fundamental points only are dealt with, to the welcome exclusion of a mass of material the interest of which is almost entirely academic. Very speculative developments, such as that of Einstein in connection with gravitation, are omitted, and the author is thereby enabled to give a very clear view of the real implications of the Principle.

\section{THE DEVELOPMENT OF MAN.}

Heredity and Environment in the Development of Men. By Prof. E. G. Conklin. Pp. xiv + 533. (Princeton: University Press; London: Oxford University Press, I9I5.) Price $8 s .6 d$. net.

$A$ DDRESSING a general audience rather than A a scientific gallery, Prof. Conklin deals in six lectures with the development of Man. In the first chapter he shows that development is the result of intrinsic factors, implied in the organisation of the germ-cells, and of extrinsic factors, the environmental conditions. The germcell is a living individuality, and development is one of its functions. New materials and qualities appear in increasing complexity, and this is due to active combinations and interactions under environmental influence. The hereditary germinal organisation is very complex, but development is no mere unfolding or unpacking. It includes processes of "creative synthesis."

The second chapter is devoted to the germcells and their organisation. "Development is progressive and co-ordinated differentiation of the germinal organisation, by which it is transformed into the adult organisation." Different kinds of substances are formed epigenetically; these are localised and isolated by intra-cellular movements NO. 2388, VOI. 95] and differential cytoplasmic divisions; and they are eventually transformed into various permanent structures.

The third chapter deals with the modes of inheritance, with special reference to Man. "Blending" is still retained on trial, but it is shown that "the principles of Mendel have served as an Ariadne thread to guide science through the maze of apparent contradictions and exceptions in which it was formerly lost." In the next rhapter the author treats of the influence of the environment, and is more than usually careful in his analysis. $\mathrm{He}$ distinguishes the different kinds of developmental stimuli, the different times of their operation, and their varied results. There is a useful recognition of functional activity as a factor in development. "Nurture," it is argued, means much as a condition of individual development, but little as a transforming factor in evolution. For Man, however, with his social heritage, the evolution of the environment must corroborate eugenic improvements of the breed. In this and in the next chapter, which is devoted to a consideration of eugenics, the author turns repeatedly to the idea that environmental changes, saturating into the germ-cells, may incite heritable variations in the germinal organisation. The discussion of eugenics is restrained and wise. It is possible to improve the human breed (I) by preventing the seriously defective from reproducing; (2) by cultivating pride of race, and discouraging voluntary infertility on the part of those who have a goodly heritage; (3) by increasing opportunities for early and favourable marriages; and (4) by carefully conserving the best human mutations or heritable variations. But along with these eugenic endeavours there must go improvements of environment and training-including, preeminently, the development of control and goodwill.

In the concluding pages Prof. Conklin explains how he, as a biologist, finds between the fatalistic and voluntaristic extremes a middle way which leads to action. We venture to commend the wise and stimulating discussion of the determinism involved in the creature's hereditary and nurtural relations and of the other side to this. The book is marked by sound judgment, firmness and clearness of treatment, and a vigorous buoyancy. It is to be strongly recommended to those who wish to understand the facts of human development in their relation to the larger problems of human life. The volume is well got up, effectively illustrated, and provided with a carefully selected bibliography and an unusually good glossary as well as a full index. 